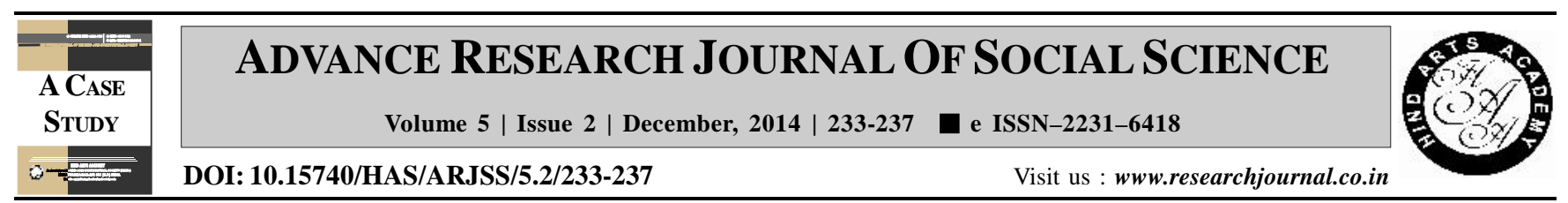

\title{
Adoption of recommended cultivation practices for the onion (Allium cepa.) growers
}

R.N. Bhise*, N.M. Kale ${ }^{1}$ and Y.J. Waghmode

Department of Extension Education, Dr. Balasaheb Sawant Konkan Krishi Vidyapeeth, Dapoli, RATNAGIRI (M.S.) INDIA

${ }^{1}$ Department of Extension Education, Dr. Panjabrao Deshmukh Krishi Vidyapeeth, AKOLA (M.S.) INDIA

(Email: rushikesh.bhise@ yahoo.in)

\section{ARTICLE INFO :}

Received : 15.09 .2014

Accepted : 23.11 .2014

KEY WORDS :

Adoption, Training need, Knowledge

HOW TO CITE THIS ARTICLE :

Bhise, R.N., Kale, N.M. and Waghmode, Y.J. (2014). Adoption of recommended cultivation practices for the onion (Allium cepa.) growers, Adv. Res. J. Soc. Sci., 5 (2) : 233-237.

*Author for correspondence

\begin{abstract}
The present research study was based on exploratory research design of social research. The field survey was carried out in Akot tahsil under Akola district of Vidharbha region of Maharashtra State during 2011-2012. For ascertaining the Adoption level of the farmers about recommended cultivation practices for onion crop. The results revealed that over half $(61.00 \%)$ of farmers had medium level of adoption of recommended cultivation practices for onion crop followed by 22.00 per cent and 17.00 per cent of the farmers had low and high level of adoption. In this context, it was implied that the information regarding recommended cultivation practices should be disseminated to the farmers by extension functionaries, KVK's, NGO's, through demonstrations, workshops, distributing printed material like leaflets; folders; etc. It will lend a hand for increasing adoption, perception, knowledge and ultimately the yield level onion crop.
\end{abstract}

